\title{
Ingestive verbs, causatives, and object symmetry in Lubukusu
}

\author{
Kyle Jerro*0 \\ University of Essex
}

\section{Introduction}

The question of object symmetry compares the grammatical function of two objects in a ditransitive predicate. Of particular interest has been derived ditransitives where a valencychanging morpheme increases the valency of a transitive verb. The central question is whether an object licensed by the base verb and an object licensed by e.g. an applicative morpheme have the same grammatical function. Several aspects of grammar have been proposed to account for object (a)symmetries, such as syntactic differences, especially the height of argument licensing heads (Baker 1988, Ngonyani 1996, McGinnis 2001, Harley 2002, McGinnis \& Gerdts 2003, Jeong 2007), differences in thematic role (Bresnan \& Moshi 1990, Alsina \& Mchombo 1993), and the animacy and person features of the two objects (Morolong \& Hyman 1972, Aranovich 2009, Baker et al. 2012). In this paper, I make the novel claim that verb meaning is an additional component in determining symmetry. ${ }^{1}$ I present a case study from Lubukusu (Bantu; Kenya) where the general pattern with morphological causatives is asymmetry, but caused ingestive verbs are symmetrical.

I sketch a brief analysis of these facts by building on the observation that ingestive verbs in many languages behave distinctly under causativization (Masica 1976, Amberber 2002, Næss 2007, 2009, Krejci 2012). I propose that the symmetry of caused ingestives in Lubukusu follows from a principled difference in the lexical semantics of these verbs; adopting an approach from Krejci (2012), I analyze ingestive verbs as inherent reflexive events wherein an agent causes him- or herself to digest something. With caused ingestives, there is a delinking of the reflexive relationship between the causer and the ingester, 
and thus caused ingestives already have a causal relationship in their event structure. This contrasts with other verbs for which causativization adds a wholesale new causal subevent. It is this difference in the lexical semantic nature of the verb that provides a starting point for explaining the divergent behavior of caused ingestive verbs with respect to object symmetry.

\section{The Morphological Causative and Object Symmetry}

Lubukusu is a Bantu language spoken in western Kenya (Mutonyi 2000, Wasike 2007, Sikuku 2011). Causatives in Lubukusu are marked by the morpheme - esy (or the allomorph -isy, determined by vowel harmony), and with many verbs the objects are asymmetrical. For example, with the verb khu-pa 'to hit' in (1), the causee object can be the subject of the passive in (2a), but the verbal object cannot in $(2 b){ }^{2}$

(1) O-mw-ekesi $\emptyset$-a-p-isy-a o-mu-khangarani li-sisi. 1-1-teacher 1.SBJ-PST-hit-CAUS-FV 1-1-warrior 5-wall

'The teacher made the warrior hit the wall.'
a. O-mu-khangarani $\emptyset$-a-p-isy-ibw-a
li-sisi ne o-mw-ekesi.
1-1-warrior
1.SBJ-PST-hit-CAUS-PASS-FV 5-wall by 1-1-teacher

'The warrior was made to hit the wall by the teacher.'
b??Li-sisi ly-a-p-isy-ibw-a omu-khangarani ne o-mw-ekesi.
5-wall 5.SBJ-PST-hit-CAUS-PASS-FV 1-1-warrior by 1-1-teacher

'The wall was made to be hit by the warrior by the teacher.'

The data in (2) parallel the symmetry facts for several other elicited verbs, such as khukhala 'to cut', khu-funa 'to break', and khu-ombakha 'to build'. I focus on passivization as a diagnostic in the present paper for considerations of space, though various other diagnostics are cited in the literature, such as object marking, relativization, and word order (Baker 1988, Marantz 1993, Alsina \& Mchombo 1993, Schadeberg 1995, Rugemalira 
1991, Ngonyani 1996, 1998, Moshi 1998, Thwhala 2006, Reidel 2009, Zeller \& Ngoboka 2006, Marten et al. 2007, Jerro 2015, 2016b).

With the ingestive verbs khu-nywa 'to drink' and khu-lia 'to eat', on the other hand, both objects can appear as the subject of the passive, as shown in (4) for the verb khu-nywa 'to drink' and in (5) for khu-lia 'to eat'. ${ }^{3}$

(3) Wafula Ø-a-nyw-esy-a Wekesa ka-ma-lwa. Wafula 1.SBJ-PST-drink-CAUS-FV Wekesa 6-6-beer

'Wafula made Wekesa drink the beer.'
a. Wekesa ฤ-a-nyw-esy-ebw-a
ka-ma-lwa ne Wafula.

Wekesa 1.SBJ-PST-drink-CAUS-PASS-IMP 6-6-beer by Wafula

'Wekesa was made to drink the beer by Wafula.'

b. Ka-ma-lwa k-a-nyw-esy-ebw-a Wekesa ne Wafula.

6-6-beer 6.SBJ-PST-drink-CAUS-PASS-IMP Wekesa by Wafula

'The beer was made to be drunk by Wekesa by Wafula.'

(5) Wafula $\emptyset$-a-lis-isy-e o-mw-ana ku-mu-chele.

Wafula 1.SBJ-PST-eat-CAUS-FV 1-1-child 3-3-rice

'Wafula fed the child rice.'
a. O-mw-ana $\emptyset$-a-l-isy-ibw-e
ku-mu-chele.
1-1-child 1.SBJ-PST-eat-CAUS-PASS-FV 3-3-rice
'The child was fed rice.'
b. Ku-mu-chele ku- $\emptyset-l-i s y-i b w-e \quad o-m w$-ana.
3-3-rice 3S-PST-eat-CAUS-PST-FV 1-1-child
'The rice was fed to the child.'

The difference in symmetry between ingestive verbs and other transitive verbs is evidence that verb meaning plays a role in the argument realization facts of object symmetry a heretofore unnoticed fact in the literature. The question that arises, then, is why this particular class of verbs behaves differently with respect to object symmetry, and I outline a preliminary account based around the lexical semantics of ingestive verbs, which in many languages behave differently with respect to causativization. ${ }^{4}$ 


\section{Ingestive Verbs Cross-Linguistically}

Several unrelated languages treat ingestive verbs distinctly from other syntactically transitive verbs, e.g. Malayalam (Mohanan 1983:105-106), Berber (Guerssel 1986:36ff), Tariana (Aikhenvald 2000), Jarawara (Dixon 2000), Cora (Vasquez Soto 2002), and Hindi (Masica 1976:46), among others (see also Nedjalkov \& Silnitsky 1973, Shibatani 2002, and Shibatani \& Pardeshi 2002). Consider an example from Amharic (Semitic; Ethiopia), which has two distinct causative morphemes: $a$ - and $a$ - (Amberber 2000, 2002). The causative $a$ - is reserved for intransitives, as in (7) where the prefix cannot appear with the transitive verb $k^{\prime w}$ วrrət'ว 'cut'.
a. k'omə 'stand (intr)' $\rightarrow a-k$ 'omə 'stand (tr)'
b. $\quad k^{\prime w}$ ərrət'ə 'cut' $\rightarrow * a-k^{\prime w}$ ərrət'ə

(Amharic; Amberber 2002:2,(2))

The prefix $a s^{-}$, on the other hand, appears with both transitives and intransitives:
a. mət't'a 'come' $\rightarrow a s-m \partial t$ 't' $a$ 'make $x$ come'

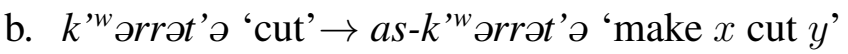

(Amharic; Amberber 2002,2,(3))

Given that the verb bolla 'eat' is syntactically transitive, it is not expected to appear with the prefix $a-$, but this morpheme can, in fact, be used with bəlla 'to eat', as in (9).

(9) Aster ləmma-n dabbo a-balla-čč-iw.

Aster Lemma-ACC bread CAUS-eat-PF-3F-3MO

'Aster fed Lemma some bread.'

(Amharic; Amberber 2002:3,(5))

This pattern is found with other predicates describing both literal and figurative ingestion, such as: lasə 'lick', t’əba 'suck', k’əmməsə 'taste', lək'k’əmə 'pick up', $t^{w}$ ’rrəsə 'take a 
mouthful', and gat'ə 'graze' (Amberber 2002:3). In sum, ingestive verbs pattern distinctly from other transitive verbs despite their syntactic transitivity.

To capture the divergent syntax of ingestive verbs, Krejci (2012) makes the case that ingestive verbs are semantically reflexive, drawing on both cross-linguistic and lexical semantic evidence. First, ingestive verbs in some languages, such as the Bolivian language Movima (Haude 2006), pattern with inherent reflexives in appearing with middle morphology. Further, Krejci shows that while the default in many languages is for inherent reflexive verbs (e.g. to wash) to be derived from causatives via reflexivization (such as Spanish lavarse 'to wash' (intr.) from lavar 'to wash' (tr.)), in other languages, inherent reflexives are the base form that causatives are derived from (such as Hindi causative uth-aa 'to raise' from the intransitive $u t h$ 'to rise'; Masica 1976:319). For these latter languages, causative morphology does not add a new periphrastic causative subevent to the verb, but rather delinks the reflexive nature of the base verb. Krejci shows that cross-linguistically, ingestives often pattern with inherent reflexives in the directionality of marking with respect to causatives. Finally, Krejci looks at lexical entailments of ingestive verbs in English and Marathi and concludes that there is a bieventive, reflexive meaning in the event structure of ingestive verbs ( $c f$. Amberber 2002 and Jackendoff 1990:53-55,253). In other words, the single subject of eat is associated with various lexical entailments (e.g. the manipulation of food and the chewing of the food) that are split across two arguments in the predicate feed.

\section{Towards an Analysis of Lubukusu Object Symmetry}

I extend Krejci's analysis of ingestive verbs to Lubukusu in order to serve as a starting point for understanding their distinct pattern with object symmetry. Specifically, caused ingestives retain the ditransitive event structure of the non-caused verb, which is distinct from the causatives of most verbs where the causal morpheme is a productive operator 
which adds a new causal subevent to the event structure of the verb. I outline this account using a typed lambda calculus in which hierarchical relationships of the verb's meaning are defined via lexical entailments of the verb (adopting the formal approach in Jerro 2018). I assume a domain of discourse $U$ that consists of two major sorts: the subset $U_{I}$ of individuals and $U_{E}$ of eventualities. Variables in the set $\mathrm{U}_{I}$ are $x, y$, and $z$. The variables $v, s$, and $e$ represent events. ${ }^{5}$ The event variable $e$ is a complex event that is the summation of all subevents of the predicate, and each subevent is causally linked to the other subevents in $e$. Finally, subevents within $e$ are causally ordered with respect to one another as specified by the lexical entailments of the verb. These constraints are indicated by the relations init' and $\mathrm{fin}^{\prime}$, which state that a particular named event must be initial or final in the event $e$, respectively. Consider the denotation of khu-lia 'to eat' in (10), adapted from Krejci 2012 $(2012: 42,(37 a)) .^{6}$

$$
\begin{aligned}
& \llbracket k h u l i a \rrbracket:=\lambda x \lambda y \lambda s \lambda v \lambda e\left[a g^{\prime}(v, y) \wedge t h^{\prime}(v, x) \wedge a g^{\prime}(s, y) \wedge t h^{\prime}(s, x) \wedge s \subset e \wedge\right. \\
& \left.v \subset e \wedge \text { manipulating.food }(v) \wedge f \operatorname{fin}^{\prime}(s, e) \wedge \diamond \operatorname{digesting}^{\prime}(s)\right]
\end{aligned}
$$

In (10) there are two subevents: a causing event $v$ of manipulating food and a caused change-of-state $s$ of prospective digestion. Crucially, the agent of the causing event (the manipulator of the food) and the agent of the change of state (the ingester) are the same individual - hence the reflexive nature of these verbs. ${ }^{7}$ The change-of-state $s$ must be final in the causal chain, as specified by $\operatorname{fin}^{\prime}(s, e)$. Consider the sentence in (11a) and its semantics in (11b).

a. Wafula $\emptyset$-a-li-le ku-mu-chele. Wafula 1.SBJ-PST-eat-FV 3-3-rice

'Wafula ate the rice.'

b. $\exists s \exists v \exists e\left[a g^{\prime}(v\right.$, wafula $) \wedge t h^{\prime}\left(v\right.$, rice $\left.^{\prime}\right) \wedge a g^{\prime}(s$, wafula $) \wedge t h^{\prime}($ s, rice $) \wedge$ $s \subset e \wedge v \subset e \wedge$ manipulating.food $\left.(v) \wedge \operatorname{fin}^{\prime}(s, e) \wedge \diamond \operatorname{digesting}^{\prime}(s)\right]$ 
This sentence means that Wafula acted to manipulate food, and as a result of this action, he (potentially) digests the rice.

The analysis of khu-lia 'eat' as a bieventive, causative verb predicts that it should be possible to separate the causing event from the result state (compared with non-causative, monoeventive verbs such as khu-chekha 'to laugh' where such a division is not possible). A classic diagnostic for this is ambiguity under again-modification (Morgan 1969, McCawley 1973:342-343, Dowty 1979:250ff, Beck \& Johnson 2004:106ff, Krejci 2012:61-71). A bieventive predicate should be ambiguous between two possible readings: a restitutive reading where again has scope over just the result and a repetitive reading where again has scope over the entire event. ${ }^{8}$

(12) [Context: The rice is cursed so that it regenerates after having been eaten.]

Wekesa $\emptyset$-a-l-ile ku-mu-chele lundi.

Wekesa 1.SBJ-PST-eat-FV 3-3-rice again

'Wekesa ate the rice again.'

The sentence in (12) has both readings. On the repetitive reading lundi 'again' takes scope over the entire event (i.e. Wekesa performing the entire eating event again). Crucially, there is also the restitutive reading: Wekesa did not eat the rice the first time (e.g. Wekesa's friend Wafula ate the rice, and then the rice regenerated to its original state), and then Wekesa ate it a second time. The ambiguity in scope over the subevents supports the analysis of khulia 'to eat' as having a bieventive, causal structure. By means of comparison, consider the monoeventive verb khu-chekha 'to laugh' in (13).

(13) Wekesa $\emptyset$-a-chekh-ele lundi.

Wekesa 1.SBJ-PST-laugh-FV again

'Wekesa laughed again.'

In (13), there is only the repetitive reading: Wekesa laughed before and then laughed again. 
A diagnostic for probing causation is with modifiers meaning 'by oneself' — crucially on the reading that the event occurred without external help (Siewierska 1984:78-79, Chierchia 2004:42-44, Koontz-Garboden 2009:106-110, Krejci 2012:87-90, Beavers \& Zubair 2013:15-16). ${ }^{9}$ The ability for omwene 'by oneself' to appear with khu-lia 'to eat' in (14) is further evidence of a bieventive analysis of the verb khu-lia 'to eat'.

(14) Wekesa $\emptyset$-a-l-ile omwene.

Wekesa 1.SBJ-PST-eat-FV by.himself

'Wekesa ate by himself (i.e. Wekesa ate without external help).'

(15) \#Wekesa $\emptyset$-a-chekh-ele omwene.

Wekesa 1.SBJ-PST-laugh-FV by.himself

'Wekesa laughed by himself.'

The infelicity of omwene with the monoeventive verb khu-chekha 'to laugh' in (15) is evidence that the modifier indeed probes causation. From these diagnostics, I conclude that ingestive verbs in Lubukusu have a bieventive, causative semantics, as described by the denotation of khu-lia 'to eat' in (10).

Returning to caused ingestives, let us consider the causative khu-l-isy-a 'to feed'. Following Krejci's analysis of anti-reflexivization, there are crucially no additional subevents added to the event, but instead, the causer and ingester (which are the same individual for khu-lia 'to eat') are two distinct individuals in the causative in (16). ${ }^{10}$

$$
\begin{aligned}
& \llbracket k h u l i s y a \rrbracket:=\lambda y \lambda x \lambda z \lambda s \lambda v \lambda e\left[a g^{\prime}(v, z) \wedge t h^{\prime}(v, x) \wedge a g^{\prime}(s, y) \wedge t h^{\prime}(s, x) \wedge\right. \\
& \left.s \subset e \wedge v \subset e \wedge \text { manipulating.food }(v) \wedge \operatorname{fin}^{\prime}(s, e) \wedge \diamond \operatorname{digesting}^{\prime}(s)\right]
\end{aligned}
$$

The event structure in (16) is the same as (10), with the crucial difference being that the agent of the event of manipulating food is not the same as the participant that prospectively digests it. Consider the reading of khu-l-isy-a 'to feed' in (17). 
a. Wafula $\emptyset$-a-lis-isy-e o-mw-ana ku-mu-chele.

Wafula 1.SBJ-PST-eat-CAUS-FV 1-1-child 3-3-rice

'Wafula fed the child rice.'

\#'Wafula made the child eat rice.'

b. $\exists s \exists v \exists e\left[a g^{\prime}(v\right.$, wafula $) \wedge t h^{\prime}\left(v\right.$, rice $\left.^{\prime}\right) \wedge a g^{\prime}\left(s, \operatorname{child}^{\prime}\right) \wedge t h^{\prime}\left(s\right.$, rice $\left.^{\prime}\right) \wedge$

$s \subset e \wedge v \subset e \wedge$ manipulating.food $(v) \wedge \operatorname{fin}^{\prime}(s, e) \wedge \diamond$ digesting $\left.^{\prime}(s)\right]$

In (17), the reading is that Wafula is feeding the rice to the child, e.g. by taking the rice and putting it directly into the child's mouth; crucially, the agent of the manipulation of the food and the prospective digester are distinct. Note that the reading is not that of a periphrastic causative, i.e. where someone caused the child to eat rice. Thus with khu-l-isy$a$ 'to eat' there is no additional causal subevent in the event structure as compared to the event structure of the base verb, and the nature of causation is the same as the non-caused variant khu-lia 'to eat'.

Turning to transitives like khu-funa 'to break', I assume a periphrastic causation analysis for these verbs where the causative adds a new causer subject (via an additional causal subevent) to the clause. Consider the meaning of the causative morpheme in (18), developed from an analysis of the cognate morpheme -ish in Kinyarwanda (Jerro 2018). ${ }^{11}$

$$
\begin{aligned}
& \llbracket-e s y \rrbracket:=\lambda P \lambda x_{1} \ldots \lambda x_{n} \lambda z \lambda e_{1} \ldots \lambda e_{m}\left[P ( x _ { 1 } \ldots x _ { n } , e _ { 1 } \ldots e _ { m } ) \wedge \exists e ^ { \prime } \left[e^{\prime} \subset e_{m} \wedge\right.\right. \\
& \left.\left.a g^{\prime}\left(e^{\prime}, z\right) \wedge i n i t^{\prime}\left(e^{\prime}, e\right)\right]\right]
\end{aligned}
$$

Here, the causative morpheme licenses a new causative subevent which precedes the subevents described by the verb. I assume the denotation in (19) for the verb khu-funa 'to break', where there is an agent $x$ that is linked to the causing event $v$ which causes the result $s$ of the object $y$ being broken.

$$
\begin{aligned}
& \llbracket k h u f u n a \rrbracket:=\lambda x \lambda y \lambda s \lambda v \lambda e\left[a g^{\prime}(v, y) \wedge t h^{\prime}(s, x) \wedge v \subset e \wedge s \subset e \wedge b_{\text {beaking }}(v) \wedge\right. \\
& \left.\operatorname{broken}^{\prime}(s) \wedge f \operatorname{fin}^{\prime}(s, e)\right]
\end{aligned}
$$


Composing the meaning of the verb khu-funa 'to break' and that of -esy gives (20).

$$
\begin{aligned}
& \lambda x \lambda y \lambda z \lambda s \lambda v \lambda e\left[a g^{\prime}(v, y) \wedge t h^{\prime}(s, x) \wedge v \subset e \wedge s \subset e \wedge \operatorname{breaking}^{\prime}(v) \wedge\right. \\
& \left.\operatorname{broken}^{\prime}(s) \wedge \operatorname{fin}^{\prime}(s, e) \wedge \exists e^{\prime}\left[e^{\prime} \subset e_{m} \wedge a g^{\prime}\left(e^{\prime}, z\right) \wedge \operatorname{init}^{\prime}\left(e^{\prime}, e\right)\right]\right]
\end{aligned}
$$

The denotation in (20) corresponds to a sentence like that in (21).

a. Wafula a-kha-fun-isy-a bi-kombe o-mw-ana.

Wafula 1.SBJ-TNS-break-CAUS-FV 8-cup 1-1-child

'Wafula is causing the child to break the cups.'

Here, there is a causing event $e^{\prime}$ in $e$ that precedes the subevents described by the verb khu-funa 'to break', as is typical of periphrastic causatives. Thus khu-l-isy-a 'to feed' and khu-fun-isy- $a$ 'to cause to break' differ in the nature of causation: with the former, there is no additional causal subevent, and the ditransitive event structure is not derived; with the latter, however, a new causal subevent (and associated causer argument) is added to the event structure, deriving a ditransitive event structure. I propose that it is this difference in how the causative verbs arise which correponds to the two classes' distinct symmetry properties.

Because caused ingestive verbs have a non-derived ditransitive event structure, it is expected that other semantically ditransitive verbs should pattern similarly with respect to symmetry. This is borne out with the verb khu-wa 'to give', which — parallel to caused ingestives - is symmetrical under passivization in (22). ${ }^{12}$

a. Si-tabu sy-a-Ø-ebw-a Wekesa (ne Wafula).

7-book 7.SBJ-PST-give-PASS-FV Wekesa by Wafula

'The book was given to Wekesa by Wafula.'

b. Wekesa $\emptyset$-a- $\emptyset$-ebw-a si-tabu (ne Wafula).

Wekesa 1.SBJ-PST-give-PASS-FV 7-book by Wafula

'Wekesa was given a book by Wafula.' 
The symmetrical behavior of khu-wa 'to give' fits with the analysis of caused ingestives as ditransitive verbs, as these verbs pattern the same as a lexically ditransitive verb in the language. ${ }^{13}$

\section{Conclusion}

In this paper, I have presented evidence that in Lubukusu the nature of causation with ingestive verbs is an operation of anti-reflexivization, which is distinct from the general causative operation in the language which adds a wholesale new causal subevent. I proposed that this distinction in the semantics of causation provides a starting point for analyzing the difference of object symmetry. More broadly, I have shown that object symmetry can vary according to verb class, an empirical fact that has not been considered in previous work on object symmetry. Furthermore, verb meaning has been shown to determine the thematic role and syntactic function of other valence-increasing morphemes such as locative applicatives in Kinyarwanda (Jerro 2016a) as well as influence whether a full object or object prefix will appear, such as in the Bantu languages Kinyakyusa (Lusekelo 2012) and Kiluguru (Marten \& Ramadhani 2001). Thus the influence of verb meaning on argument realization is an important factor to consider in future work on valency-changing morphology.

Many questions remain, in particular an explanation of what determines the sizable variation in object (a)symmetries across languages. However, what is coming to light from both the present work and other studies is that a comprehensive theory of object symmetry requires an admixture of several interrelated factors in addition to syntax, such as the noun cast of the objects (Morolong \& Hyman 1972, Aranovich 2009, Baker et al. 2012), the thematic role of the applied object (Baker 1988, Bresnan \& Moshi 1990, Alsina \& Mchombo 1993, Ngonyani 1996, McGinnis 2001, McGinnis \& Gerdts 2003, Jeong 2007), and — as

I argue here - the meaning of the base verb. The interrelations of these different aspects 
of grammar opens up a rich domain of inquiry for future work.

\section{References}

Aikhenvald, A. (2000). Transitivity in Tariana. In Dixon, R. M. W. \& Aikhenvald, A. (eds.), Changing valency: Case studies in transitivity, Cambridge: Cambridge University Press. 312-331.

Alsina, A. \& Mchombo, S. (1993). Object asymmetries and the Chicheŵa applicative construction. In Mchombo, S. (ed.), Theoretical aspects of Bantu grammar, Stanford: CSLI Publications. 17-45.

Amberber, M. (2000). Valency-changing and valency encoding devices in Amharic. In Dixon, R. M. W. \& Aikhenvald, A. (eds.), Changing valency: Case studies in transitivity, Cambridge: Cambridge University Press. 312-331.

Amberber, M. (2002). Quirky alternations of transitivity: The case of ingestive predicates. In Amberber, M. \& Collins, P. (eds.), Language universals and variation, Westport, CT: Praeger. 1-19.

Aranovich, R. (2009). Animacy effects and locative marking in Shona applicatives. In Butt, M. \& King, T. (eds.), Proceedings of the LFG09 conference, Stanford: CSLI Publications. 65-84.

Baker, M. (1988). Theta theory and the syntax of applicatives in Chichewa. Natural Language and Linguistic Theory 6. 353-389.

Baker, M., Safir, K. \& Sikuku, J. (2012). Sources of (a)symmetry in Bantu double object constructions. In Arnett, N. \& Bennett, R. (eds.), Proceedings of the 30th West Coast Conference on Formal Linguistics, Somerville, MA: Cascadilla Proceedings Project. 5464.

Beavers, J. \& Zubair, C. (2013). Anticausatives in Sinhala: Involitivity and causer suppression. Natural Language and Linguistic Theory 31. 1-46.

Beck, S. \& Johnson, K. (2004). Double objects again. Linguistic Inquiry 35. 97-123.

Bresnan, J. \& Moshi, L. (1990). Object asymmetries in comparative Bantu syntax. Linguistic Inquiry 21. 147-185.

Chierchia, G. (2004). A semantics of unaccusatives and its syntactic consequences. In Alexiadou, A., Anagnostopoulou, E. \& Everaert, M. (eds.), The unaccusativity puzzle: Explorations of the syntax-lexicon interfact, Oxford: Oxford University Press. 288-331. 
Cooper, R. (1976). Lexical and non-lexical causatives in Bantu. In Shibatani, M. (ed.), Syntax and semantics vol. 6, New York: Academic Press. 312-24.

Dixon, R. M. W. (2000). A typology of causatives: Form, syntax, and meaning. In Dixon, R. M. W. \& Aikhenvald, A. (eds.), Changing valency: Case studies in transitivity, Cambridge: Cambridge University Press. 30-83.

Dowty, D. (1979). Word meaning and Montague grammar. Dordrecht: Kluwer.

Guerssel, M. (1986). On Berber verbs of change: A study of transitivity alternations. Cambridge, MA: MIT Press, Lexicon Project, Center for Cognitive Science.

Harley, H. (2002). Possession in the double object construction. In Pica, P. \& Rooryck, J. (eds.), Linguistic variation yearbook 2, Amsterdam: John Benjamins. 31-70.

Haude, K. (2006). A grammar of Movima. Ph.D. dissertation, University of Nijmegen, Nijmegen.

Jackendoff, R. (1990). Semantic structures. Cambridge, MA: MIT Press.

Jeong, Y. (2007). Applicatives: Structure and interpretation from a minimalist perspective. Amsterdam: John Benjamins.

Jerro, K. (2013). Argument structure and the typology of causatives in Kinyarwanda: Explaining the causative-instrumental syncretism. MA Report: University of Texas at Austin.

Jerro, K. (2015). Revisiting object symmetry in Bantu. In Ruth Kramer, O. T. B., Elizabeth Zsiga (ed.), The selected proceedings of the 44th Annual Conference on African Linguistics, Somerville, MA: Cascadilla Proceedings Project. 130-145.

Jerro, K. (2016a). Locative applicatives and the semantics of verb class. In Payne, D. L., Pacchiarotti, S. \& Bosire, M. (eds.), Diversity in African languages: Selected papers from the 46th Annual Conference on African Linguistics. Berlin: Language Science Press. vol. 1, 289-308.

Jerro, K. (2016b). The syntax and semantics of applicative morphology in Bantu. Ph.D. dissertation, The University of Texas at Austin, Austin, TX.

Jerro, K. (2018). The causative-instrumental syncretism. Journal of Linguistics 54.

Koontz-Garboden, A. (2009). Anticausativization. Natural Language and Linguistic Theory $27.77-138$.

Krejci, B. (2012). Causativization as antireflexivization: A study of middle and ingestive verbs. M.A. Report: University of Texas at Austin. 
Lusekelo, A. (2012). Object marking in Nyakyusa language: Exploration for Optimality Theory. Ph.D. dissertation, University of Botswana, Gaborone, Botswana.

Marantz, A. (1993). Implications of asymmetries in double object constructions. In Mchombo, S. (ed.), Theoretical aspects of Bantu grammar, Stanford: CSLI Publications. $113-148$.

Marten, L., Kula, N. \& Thwhala, N. (2007). Parameters of morphosyntactic variation in Bantu. Transactions of the Philological Society 105. 253-338.

Marten, L. \& Ramadhani, D. (2001). An overview of object marking in Kiluguru. SOAS Working Papers in Linguistics 11. 259-275.

Masica, C. (1976). Defining a linguistic area: South Asia. Chicago: University of Chicago Press.

McCawley, J. (1973). Syntactic and logical arguments for semantic structures. In Farjimura, O. (ed.), Three dimensions in linguistic theory, Tokyo: TEC Corp. 259-376.

McGinnis, M. (2001). Variation in the phase structure of applicatives. Linguistic Variation Yearbook 1. 105-146.

McGinnis, M. \& Gerdts, D. (2003). A phase-theoretic analysis of Kinyarwanda multiple applicatives. In Proceedings of the 2003 canadian linguistic association annual conference department of linguistics, Université du Québec à Montréal. 154-165.

Miyagawa, S. (1984). Blocking and Japanese causatives. Lingua 64. 177-207.

Mohanan, K. (1983). Move NP or lexical rules?: Evidence from Malayalam causativization. In Levin, L., Rappaport Hovav, M. \& Zaenen, A. (eds.), Papers in LexicalFunctional Grammar, Bloomington, IN: Indiana University Linguistics Club. 47-111.

Morgan, J. (1969). On arguing about semantics. Papers in Linguistics 1. 49-70.

Morolong, M. \& Hyman, L. (1972). Animacy, objects, and clitics in Sesotho. Studies in African Linguistics 8. 199-218.

Moshi, L. (1998). Word order in multiple object constructions in KiVunjo-Chaga. Journal of African Languages and Linguistics 19. 137-152.

Mutonyi, N. (2000). Aspects of Bukusu morphology and phonology. PhD Dissertation, Ohio State University.

Nedjalkov, V. \& Silnitsky, G. (1973). The typolgy of morphological and lexical causatives. In Kiefer, F. (ed.), Trends in soviet linguistics, Boston: D. Reidel. 1-32.

Ngonyani, D. (1996). The morphosyntax of applicatives. PhD Dissertation, UCLA. 
Ngonyani, D. (1998). Properties of applied objects in Kiswahili and Kinendeule. Studies in African Linguistics 27. 67-95.

Næss, Å. (2007). Prototypical transitivity. Amsterdam: John Benjamins.

Næss, Å. (2009). How transitive are EAT and DRINK verbs? In Newman, J. (ed.), The linguistics of eating and drinking, Amsterdam: John Benjamins. 27-43.

Reidel, K. (2009). The syntax of object marking in Sambaa: A comparative Bantu perspective. Ph.D. dissertation, Leiden University.

Rugemalira, J. M. (1991). What is a symmetrical lanuage?: Multiple object constructions in Bantu. In Hubbard, K. (ed.), Proceedings of Berkeley linguistics society 17. Berkeley. 200-209.

Schadeberg, T. (1995). Object diagnostics in Bantu. In Emenanjo, N. \& Ndimele, O. (eds.), Issues in African languages and linguistics, Aba, Nigeria: National Institute for Nigerian Languages. 173-180.

Shibatani, M. (2002). Introduction: Some basic issues in the grammar of causation. In Shibatani, M. (ed.), The grammar of causation and interpersonal manipulation, Amsterdam: John Benjamins. 1-22.

Shibatani, M. \& Pardeshi, P. (2002). The causative continuum. In Shibatani, M. (ed.), The grammar of causation and interpersonal manipulation, Amsterdam: John Benjamins. $85-126$.

Siewierska, A. (1984). The passive: A comparative linguistic analysis. London: Croom Helm.

Sikuku, J. (2011). Syntactic patterns of anaphoric relations in Lubukusu: Representation and interpretation in a minimalist perspective. Ph.D. dissertation, University of Nairobi, Nairobi, Kenya.

Thwhala, N. (2006). Parameters of variation and complement licensing in Bantu. In Papers in Bantu grammar, Berlin: ZAS Papers in Linguistics. 209-232.

Vasquez Soto, V. (2002). Some constraints on Cora causative constructions. In Shibatani, M. (ed.), The grammar of causation and interpersonal manipulation, Amsterdam: John Benjamins. 197-244.

Wasike, A. (2007). The left-periphery, wh-in-situ and A-bar movment in LuLubukusu and other Bantu languages. Ph.D. dissertation, Cornell University.

Wunderlich, D. (1997). Cause and the structure of verbs. Linguistic Inquiry 28. 27-68.

Zeller, J. \& Ngoboka, J. P. (2006). Kinyarwanda locative applicatives and the Minimal Link Condition. Southern African Linguistics and Applied Language Studies 24. 101-124. 


\section{Notes}

${ }^{0}$ I am grateful to John Beavers, Bonnie Krejci, Justine Sikuku, Mike Diercks, Moses Egesa, and Michael Marlo for their input and support in the writing of this paper and collecting the data within. I am deeply indebted to Benson Sindani, Krispinas Wafula, Tetas Wekesa, Rogers Wanjala, Benson Masai, Matthews Wekesa, Wekesa Wafula, Joseph Barasa, Sikuku Barasa, Obadiah Wafula, Antony Makokha, Christine Watoka, and especially Hesborn Sumba Wandabwa for judgments of the Lubukusu data provided here. Thanks especially to the Sifuna family and Hellen and Justine Sikuku for their hospitality in Kenya. Nasimile. This research was funded in part by NSF Grant \#1451566. All errors are, of course, my own.

${ }^{1}$ In Jerro (2016b:172-191) I discuss the considerable variation in symmetry facts for Lubukusu and other Bantu languages, in particular: symmetry varies across various aspects of grammar, such as (minimally) thematic role of the applied object, the diagnostic in question, and the animacy of the objects. In the present paper, I take as a starting point that it is not clear how the different aspects of symmetry interact to determine symmetry in a given clause, as previous accounts have not addressed the breadth of cross-linguistic variation. The focus of the present work is to show that there is an additional aspect that needs to be taken in to consideration (i.e. verb meaning) as future work proceeds in understanding how various aspects of grammar conspire to determine the symmetricality facts for a particular language.

${ }^{2}$ The data presented here were elicited by the author in Eldoret, Kenya in July - September 2013 and in Bungoma, Kenya in August 2015.

${ }^{3}$ The stem of the verb khu-lia 'to eat' in (5) is modified for phonological reasons.

${ }^{4}$ Baker et al. (2012) show that when the causee is a local pronoun (i.e. first- and second-person), the result is asymmetry, despite symmetry elsewhere. All the objects discussed in the present paper are intentionally third-person singular in order to control for person effects, and thus the only difference between (2) on the one hand and (4) and (6) on the other is the class of verb. Because verb class is not held constant in Baker et al. (2012), it is difficult to say how their findings coincide with the current proposal. Ultimately, I posit that both person of the object NPs as well as verb class should be considered in future work as potential factors in determining object symmetry in various languages.

${ }^{5}$ I treat all subevents as events; I do not deal directly with states here. I assume that the event variables are bound off at a later stage of the derivation.

${ }^{6}$ The conclusions in this paper are drawn from two ingestive verbs in Lubukusu: khu-lia 'to eat' and khunywa 'to drink'. I leave the question of whether the observed pattern with symmetry arises with figurative 
ingestive verbs such as learn and inherent reflexives such as wash (intr.) to future work.

${ }^{7}$ The truth conditions of khu-lia 'to eat' in Lubukusu do not entail that the food be digested, which is indicated formally with the possibility modal operator $\diamond$. For example, the digestion described in (11a) is cancellable, e.g. in a context where the food is eaten but subsequently thrown up.

${ }^{8}$ Finding an appropriate pragmatic context for ingestive verbs is somewhat difficult due to the fact that the edible object must be eaten twice, an event which does not happen in real-world contexts. The context in (12) is that the rice is cursed so that it is regenerated to appear in its original state. Krejci (2012) achieves a similar effect by the use of a video game context where players in the game eat coins that are regenerated.

${ }^{9}$ In English 'by oneself' is ambiguous between 'alone' and 'without external help'. In Lubukusu, on the other hand, there are two separate words: yeng'ene 'alone' and omwene 'without external help'. The latter is crucially what is intended for diagnosing whether causation is present in the meaning of a verb.

${ }^{10}$ There are several ways of capturing antireflexivization compositionally, which is some operation that takes a reflexive verb as input and outputs the same event structure but with non-coidentified arguments. I assume, however, that in the case of ingestive verbs in Lubukusu, the causative and noncausative verbs are in a lexical paradigmatic relationship ( $c f$. Cooper 1976 and Jerro 2013 for discussion of lexical causatives in Bantu), and so I leave a compositional analysis of antireflexivization aside here. Furthermore, I assume that the lexicalized form in (16) blocks application of the productive causative in (18), $c p$. the blocking relation between the causatives sas and sase in Japanese (Miyagawa 1984) and the blocking of causative readings with particular verbs in Kinyarwanda (Jerro 2018).

${ }^{11}$ Unlike syncretistic -ish in Kinyarwanda, the causal subevent introduced by the causative morpheme - esy in Lubukusu must be the initial subevent, indicated here with the relation $i n i t^{\prime}$, which states that the first argument is the initial subevent in the event $e$. In the framework adopted from Jerro (2018), the final argument to be picked up is mapped to subject and is the ultimate causer (cf. Wunderlich 1997).

${ }^{12}$ The verbal root is deleted in the passive in (22) for phonological reasons.

${ }^{13}$ To my knowledge, $k h u$-wa 'to give' is the only lexical ditransitive in the language, as also noted in Baker et al. (2012:57,fn.5). Should any other lexical ditransitive verbs be found, however, the expectation given the current analysis is that the objects of such a verb would also be symmetrical. 